\title{
THEORETICAL STUDY OF VARIOUS SOLVENTS EFFECT ON 5-FLUOROURACIL-VITAMIN B3 COMPLEX USING PCM METHOD
}

\author{
AZADEH KHANMOHAMMADI ${ }^{*}$ AND MARZIYEH MOHAMMADI ${ }^{b}$ \\ ${ }^{a}$ Young Researchers and Elite Club, Quchan Branch, Islamic Azad University, Quchan, Iran \\ ${ }^{b}$ Department of Chemistry, Faculty of Science, University of Vali-e-Asr, P. O. Box: 77176, Rafsanjan, Iran
}

\begin{abstract}
In this article, a detailed study of the solvent effects on the stability order, binding energy and hydrogen bond strength in 5-Fluorouracil-Vitamin B3 (FU-VB) complex is performed using M05-2X method with 6-311++G(d,p) basis set. Based on the average of the calculated H-bond energies, the H-bond strength of FUVB complex in gas phase is more than solution phase. The binding energy in solution phase is also lower than the gas phase. Therefore, the stability of the studied complex increases in solution phase with respect to the gas phase. Furthermore, the topological properties of the electron density distribution are analyzed in term of the Bader Quantum Theory of "Atoms in Molecules" (QTAIM). The natural bond orbital (NBO) method is also applied to get a more precise insight into the nature of intermolecular interactions. Finally, the solvent effect on the frontier molecular orbital energies (HOMO and LUMO), chemical potential and hardness of FU-VB complex is investigated.
\end{abstract}

Keywords: 5-Fluorouracil, Vitamin B3, Solvent effect, NBO, QTAIM.

\section{INTRODUCTION}

Intermolecular interactions are important in understanding biomolecular structures, molecular recognition, drug-receptor interactions and etc. [1]. The hydrogen bond (H-bond) is the strongest and most common intermolecular interaction and plays a very important role in nature [2-4]. It is also the subject of a vast number of theoretical and experimental studies [5-11] and its significance is conspicuous in various real life examples [12]. The H-bond is weaker than a common chemical bond, and can be encountered in solid, liquid and gas phases. This interaction is mainly dominated by electrostatic effects (dipole-dipole interactions) [1,13]. The stabilization arising from $\mathrm{H}$-bonding is primarily a result of coulombic attraction which imparts this bonding interaction with its directional nature.

5-Fluorouracil (5FU) has registered its importance in pharmaceuticals, drug delivery, enzyme synthesis, polysaccharides, transportation, allosteric regulators, coenzymes and pesticides [14-17]. It is a pyrimidine analogue drug which shows a broad spectrum of activity against solid tumors of the gastrointestinal tract, pancreas, ovary, liver, brain, and breast, etc., alone or in combination chemotherapy regimens [18]. Furthermore, the 5FU anticancer drug belongs to a bunch of medicines distinguished as antineoplastics, and it is sorted as an antimetabolite [19]. An attractive method to study 5FU retention and its metabolism both in vitro and in vivo is ${ }^{19} \mathrm{~F}$ magnetic resonance spectroscopy $\left({ }^{19} \mathrm{~F}\right.$ MRS) [20]. In fact, this method is the main tool to show $5 \mathrm{FU}$ and its conversions in tumour tissue.

Vitamin B3 (nicotinic acid or niacin) is essential to all living cells. It has the formula $\mathrm{C}_{6} \mathrm{H}_{5} \mathrm{NO}_{2}$ and belongs to the group of the pyridinecarboxylic acid. Vitamin B3 is a water-soluble vitamin, which means that the body cannot store it. The body cannot also make vitamin B3, but it can convert amino acid of the tryptophan into vitamin B3 [21]. This vitamin plays a key role in skin, digestive, and mental health, and supports the functions of more than 200 enzymes in the body. For instance, vitamin B3 might limit or stop the severity of type 1 diabetes and may play a role in HIV prevention and treatment. It is also needed to protect glutathione, an important antioxidant in the eye. Vitamin B3 deficiency can disrupt dozens of processes in the body and can lead to a disease called pellagra [22]. High amounts of vitamin B3 may also create a more optimal biochemical environment and increase recovery rate and reduce hospitalization and suicide rates. There are different interactions between vitamins and drugs and can have serious negative effects on health which must not be discarded. Preliminary data indicate that vitamin B3 (niacin) supplementation may decrease thyroid hormone levels. In addition, the drug of fluorouracil may create lower levels of vitamin B3 in the body.

Organic solvents are a common designation for a large group of more than 200 chemical compounds. They should be highly soluble and not have a toxic effect on the cells. One major advantage of using organic solvents is that they can serve as fixative agents therefore the cellular structure can stay fixed and at the same time permeabilization is carried on. Efficient fixation and permeabilization can be achieved by methanol and acetone solvents [23,24]. Acetone is used on snap-frozen tissues, precipitating them, and then methanol is used to fix. This means the cells become instantly permeabilised. Fixatives enhance the rigidity and mechanical strength of cells, which is critical to preserve the cellular structure. Membrane permeabilization is also a process of changing the permeability of cell membranes which corresponds to various physiological processes occurring within living cells. Chloroform is applied as a solvent for chemopreventive agents. The anticancer activities of chloroform extract against human breast and lung cancer cells have also been studied [25]. In addition, the results indicate that the chloroform extract is producing anticancer activity comparable with that of the standard 5-fluorouracil [26]. Ether is often used in permeabilization process, but complete removal of its residual from the cells after permeabilization is difficult to achieve [27]. It is also applied as a constructor material of some synthetic medicinal compounds. DMSO (dimethyl sulfoxide) is a organic solvent of polar and aprotic with many applications in chemical and biological research. DMSO, cell culture reagent is ideal for cryopreservation [28]. In other words, the cells need to be processed including the addition of DMSO, which enhance cell survival. Ethanol is also used as fixatives. The benefit here is that it also permeabilizes the cell membrane and is suitable for long term storage. Ethanol as a fixative is most commonly used for DNA analysis. Furthermore, ethanol and similar anesthetic drugs cause significant alterations of cells, tissues, and organs [29]. Up to 70\% of our body is made up of water. Therefore, it is a virtual factor for living cells.

The aim of the current study is to investigate the effect of different solvents on the stability order, binding energy and H-bond strength of FU-VB complex and their results compare with together and also with gas phase. The geometrical features, binding energies, topological properties and natural bond orbital (NBO) analysis are employed to elucidate the nature of intermolecular H-bond interactions. Furthermore, the molecular orbital (MO) energies and quantum molecular descriptors including electronic chemical potential $(\mu)$, global hardness $(\eta)$ and energy gap $\left(\mathrm{E}_{\mathrm{g}}\right)$ are also studied to obtain the role of MO energies charge transfer in stability of the studied complex in the different solvents.

\section{COMPUTATIONAL DETAILS}

The Gaussian 03 program suite [30] is used for quantum chemistry computations. The FU-VB complex and its monomers are optimized with M05$2 \mathrm{X}$ method and $6-311++\mathrm{G}(\mathrm{d}, \mathrm{p})$ (452 basis functions, 720 primitive Gaussians) basis set. The actual calculations are performed for different solvents with wide range of dielectric constants (including water, methanol, ethanol, ether, chloroform, acetone and DMSO). The solvent effect is evaluated by employing the self-consistent reaction field (SCRF) method with the polarized continuum model (PCM) [31]. The PCM uses the united atom cavity approach. This method defines the cavity from a set of overlapping spherical atoms having the appropriate van der Waals radii. In this study, the effects of solvent are investigated on the complex stability and intermolecular interactions and their results are compared with together and also with gas phase. The intermolecular $\mathrm{H}$-bond energies $\left(\mathrm{E}_{\mathrm{HB}}\right)$ could be estimated from the properties of bond critical points according to the Espinosa and Molins method [32]. For the investigated system, the binding energy (B.E.) is also calculated by evaluating the difference between the total energy of complex and individual monomers. The procedure for obtaining the binding energy is as follows: 


$$
\text { B.E. }=\mathrm{E}_{\mathrm{FU}-\mathrm{VB}}-\left(\mathrm{E}_{\mathrm{FU}}+\mathrm{E}_{\mathrm{VB}}\right)
$$

where B.E. is the intermolecular binding energy, $\mathrm{E}_{\mathrm{FU}-\mathrm{VB}}$ is the total energy of complex and $\mathrm{E}_{\mathrm{FU}}$ and $\mathrm{E}_{\mathrm{VB}}$ are the total energies of 5-fluorouracil and vitamin B3 monomers, respectively. Furthermore, the topological properties of electron charge density [electron density, $\rho(\mathrm{r})$, and its Laplacian, $\nabla^{2} \rho(\mathrm{r})$ ] are calculated using Bader's theory [33] at M05-2X/6-311++G(d,p) level of theory by the AIM2000 program package [34]. Also, the population analysis is performed by the natural bond orbital (NBO) method [35] on the optimized structures using NBO program [36] under Gaussian 03 program package. Finally, the analysis of highest occupied molecular orbital (HOMO) and lowest unoccupied molecular orbital (LUMO) energies is performed to evaluate the electronic properties, stability and reactivity of studied complex.

\section{RESULTS AND DISCUSSION}

Molecular geometry and binding energies

The optimized structure from interaction between 5-fluorouracil and vitamin B3 is illustrated in Figure 1. Two hydrogen bonds are observed to be formed in the complex: $\mathrm{N}-\mathrm{H} \cdots \mathrm{O}$ and $\mathrm{O}-\mathrm{H} \cdots \mathrm{O}$. As shown in Figure 1, both the $5 \mathrm{FU}$ and $\mathrm{VB} 3$ monomers can act simultaneously as agents of proton donor and proton acceptor. Therefore, the investigated complex here is coupled through double H-bonds. The most important M05-2X/6-311++G(d,p) optimized geometrical parameters of the FU-VB complex are given in Table 1. For the studied system, the H-bond distance could be considered as one of the indicators of H-bond strength [37]. It is well known that the shorter H-bond distance demonstrates the stronger H-bond energy $\left(\mathrm{E}_{\mathrm{HB}}\right)$ of the title complex.

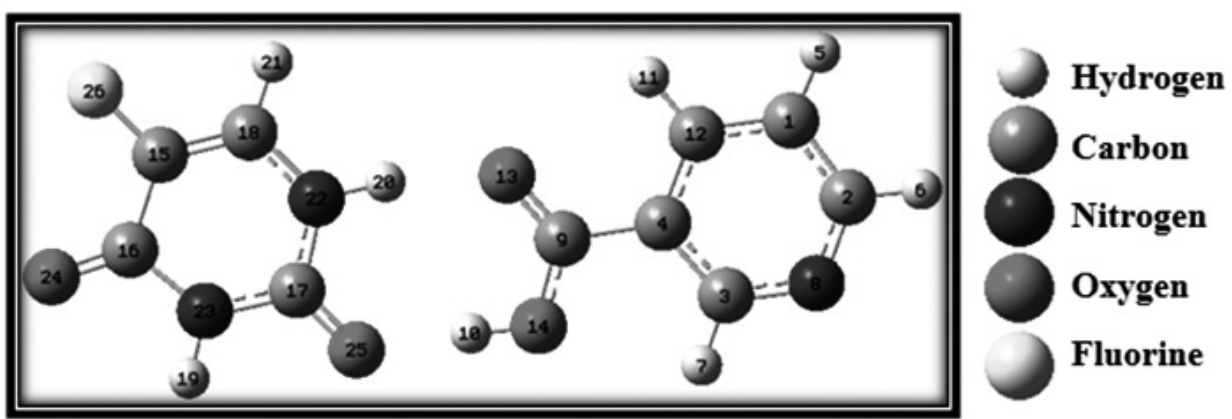

Figure 1. The optimized structure of FU-VB complex at M05-2X/6-311++G(d,p) level of theory.

Table 1. Geometrical parameters of H-bonds (length in $\AA$ ) of FU-VB complex in different solvents.

\begin{tabular}{|c|c|c|c|c|}
\hline Media & $\mathrm{N}-\mathrm{H}_{(\mathrm{FU})}$ & $\mathrm{O}^{-} \mathrm{H}_{(\mathrm{VB})}$ & $\mathrm{O}_{\mathrm{VB}} \cdots \mathrm{H}_{\mathrm{FU}}$ & $\mathrm{O}_{\mathrm{FU}} \cdots \mathrm{H}_{\mathrm{VB}}$ \\
\hline Gas phase & 1.025 & 0.992 & 1.798 & 1.679 \\
\hline Water & 1.023 & 0.995 & 1.847 & 1.660 \\
\hline DMSO & 1.023 & 0.995 & 1.846 & 1.661 \\
\hline Methanol & 1.023 & 0.995 & 1.845 & 1.661 \\
\hline Ethanol & 1.023 & 0.994 & 1.840 & 1.665 \\
\hline Acetone & 1.023 & 0.994 & 1.839 & 1.666 \\
\hline Chloroform & 1.023 & 0.994 & 1.825 & 1.673 \\
\hline Ether & 1.023 & 0.994 & 1.829 & 1.669 \\
\hline
\end{tabular}

In this study, several solvents with different polarities on the FU-VB complex are considered. The applied solvents are water, methanol, ethanol, ether, chloroform, acetone and DMSO. A PCM continuum model, at the
$\mathrm{M} 05-2 \mathrm{X} / 6-311++\mathrm{G}(\mathrm{d}, \mathrm{p})$ level of theory is used to study the solvent effects on the geometry and the intermolecular H-bond energy changes in the FU-VB complex. It is worth mentioning that $70 \%$ of cell volume is occupied with water and it can change H-bond characters such as energy, structure and electron density [38-43]. So, in this study, we have considered water as a natural compound of the cells to compare its effect with other solvents [43]

One of the most important features of the H-bond is its energy. In this article, we have estimated H-bond energy $\left(\mathrm{E}_{\mathrm{HB}}\right)$ by application of the Bader theory. The relationship between $\mathrm{H}$ - bond energy $\mathrm{E}_{\mathrm{HB}}$ and potential electron energy density at $\mathrm{H} \cdots \mathrm{O}$ bond critical point $\mathrm{V}\left(\mathrm{r}_{\mathrm{BC}}\right)$ is presented by Espinosa [32] with an equation as: $\mathrm{E}_{\mathrm{HB}} \approx 1 / 2 \mathrm{~V}\left(\mathrm{r}_{\mathrm{BCP}}\right)$. The calculated $\mathrm{H}$-bond energies of the FU-VB complex in various solvents are listed in Table 2. Our theoretical results based on the average of the calculated H-bond energies, predict the $\mathrm{H}$-bond strength of FU-VB complex in gas phase is more than solution phase and in the polar solvents is approximately the same and lower than non-polar solvents. The trend in the H-bond strength in different solvents is as follows:

ethanol $\approx$ acetone $<$ Water $\approx$ DMSO $\approx$ methanol $<$ chloroform $<$ ether

Table 2. Hydrogen bonds energies ( $\mathrm{E}_{\mathrm{HB}}$ ) and binding energy (B.E.) (in kJ/mol), stability order (S.O.) and dipole moment (in Deby) of the FU-VB complex and dielectric constant $(\varepsilon)$ of the solvents.

\begin{tabular}{|c|c|c|c|c|c|c|}
\hline Media & $\left.\mathrm{E}_{\mathrm{HB}}^{(\mathrm{O}}{ }_{\mathrm{VB}}^{\ldots} \ldots \mathrm{H}_{\mathrm{FU}}\right)$ & $\left.\mathrm{E}_{\mathrm{HB}}^{\left(\mathrm{O}_{\mathrm{FU}} \ldots \mathrm{H}\right.}{ }_{\mathrm{VB}}\right)$ & B.E. & S.O. & $\mu$ & $\varepsilon$ \\
\hline Gas phase & -40.21 & -56.84 & -72.50 & 27.53 & 4.42 & $\ldots$ \\
\hline Water & -34.32 & -60.93 & -45.86 & 0.00 & 6.02 & 80.0 \\
\hline DMSO & -34.42 & -60.83 & -46.20 & 0.33 & 5.99 & 46.8 \\
\hline Methanol & -34.53 & -60.72 & -46.56 & 0.70 & 5.96 & 32.7 \\
\hline Ethanol & -35.09 & -59.87 & -46.47 & 0.46 & 5.94 & 24.5 \\
\hline Acetone & -35.22 & -59.77 & -46.81 & 0.82 & 5.91 & 20.7 \\
\hline Chloroform & -36.85 & -58.42 & -52.78 & 6.92 & 5.50 & 4.81 \\
\hline Ether & -36.33 & -59.01 & -53.95 & 8.14 & 5.44 & 4.33 \\
\hline & & & & & & \\
\hline
\end{tabular}


As it can be seen, the H-bond strength is found to be the strongest for the non-polar solvents and the weakest for the polar solvents. The influence of the solvent on the binding energies of FU-VB complex is also considered. The binding energy is the difference between the energy of the complex and the sum of the energies of the separate component molecules. The binding energies for FU-VB complex are collected in Table 2. Our findings show that when the solvent effect is applied the binding energies of complex are significantly changed. The results show that the binding energy in solution phase is lower than the gas phase. As shown in Table 2, the most and least values of the binding energy correspond to the non-polar solvents and polar solvents, respectively. Comparing these results with the H-bond energies of FU-VB

complex shows a direct relationship between them. However, our results show that the FU-VB interaction in ether solvent is the strongest in comparison with the other solvents.

The relationship between the binding energies with dielectric constant $(\mathcal{E})$ of the solvents is also analyzed. As it is obvious from Table 2, the increment of dielectric constant of the solvents is accompanied with decreasing binding energy. In other words, results show that by increasing of the solvents polarity, the binding energy of the considered complex in these solvents decreases. Therefore, formation of FU-VB complex in ether, as non-polar solvent, is more favorable with respect to other polar solvents, energetically. Correlation between values of binding energy versus dielectric constant is shown in Figure 2.

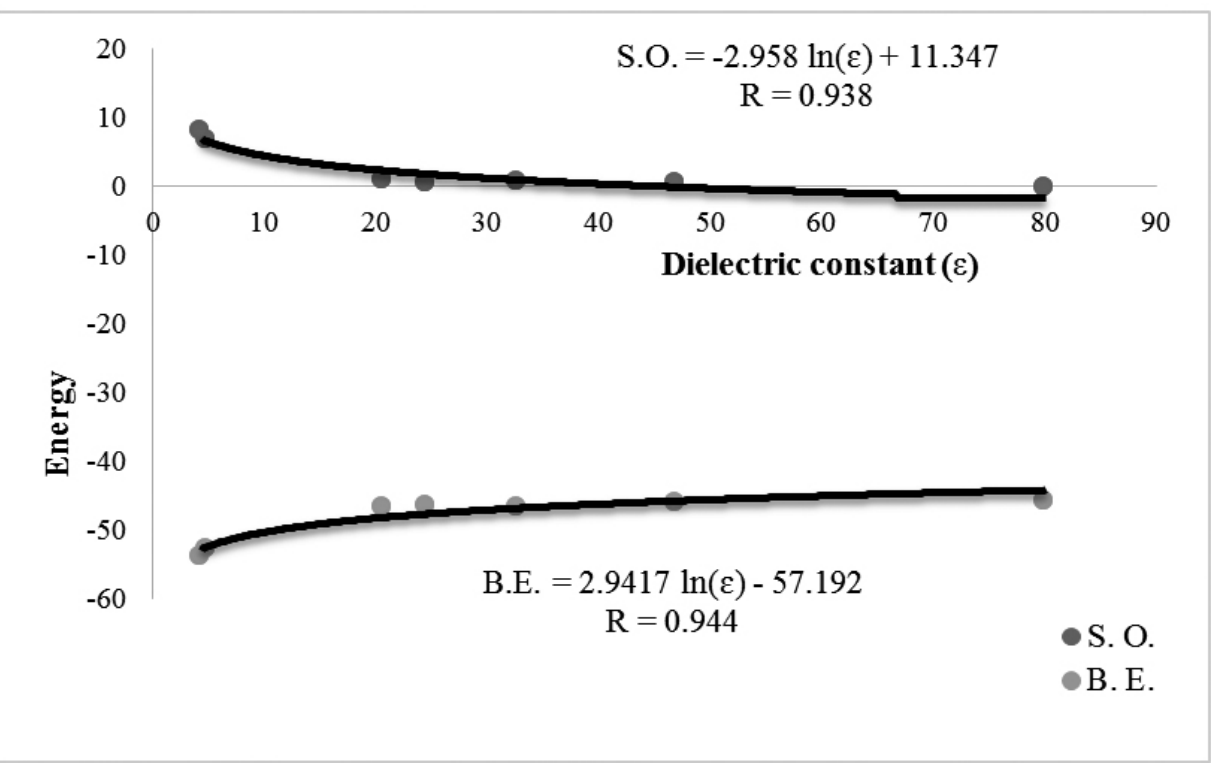

Figure 2. The relationship between S.O. and B.E. versus solvent dielectric constant.

The effect of solvent dielectric constant on the stability order (S.O.) is also investigated. Table 2 shows the FU-VB stability order values in various solvents. The result of our calculations demonstrates that the increment of solvent dielectric constant values is accompanied with increasing the stability of the FU-VB complex. Therefore, it can be seen that the most stable structure is in water solution. There is a good correlation between the dielectric constant versus the stability order in various solvents (see Figure 2). It is clear that the dielectric constants decay exponentially as stability order increases. From the obtained results, it can be concluded that the less stability is attributed to the greater strength of $\mathrm{H}$-bond and higher binding energy at $\mathrm{O} \cdots \mathrm{H}$ contacts.

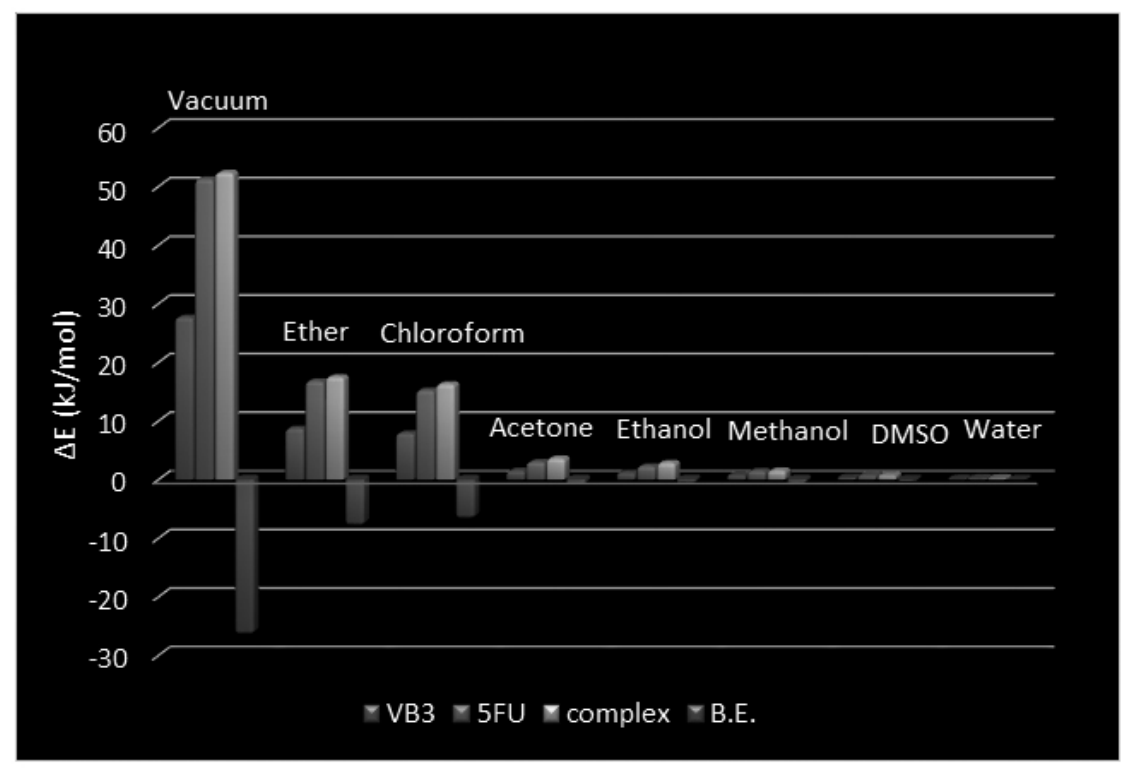

Figure 3. Dependency chart between stability order and binding energy of 5-Fluorouracil, Vitamin B3 and FU-VB complex. 
The results presented in Table 2 also indicate a linear relationship between the calculated binding energies (B.E.) and the stability order (S.O.) with an excellent correlation coefficient ( $\mathrm{R}$ is equal to 0.999 ). Therefore, B.E. could be easily computed from S.O. as follows:

$$
\text { B.E. }=-0.9661 \text { S.O. }-45.969 \text {. }
$$

This correlation with negative slope shows that the decrease in stability is accompanied with the increase in binding energy values. Although FUVB complex has the most binding energy in ether (as non-polar solvent), its stability in this solvent is lower than others. It is also obvious from Table 2 that the increase of FU-VB complex stability in polar solvents is accompanied with decrease of its binding energy in these solvents. In Figure 3, the dependency chart between the stability order and binding energy of 5FU and VB3 monomers and FU-VB complex is also observed. As shown in this Figure, the increment in stability of 5FU, VB3 and FU-VB complex is accompanied with the reduction in formation energy of FU-VB complex in the related solvents. However, these results indicate that the stability order could be useful parameter to estimate the strength of these interactions.

In this study, the dipole moment of FU-VB complex in different solvents is also investigated. Table 2 shows the dipole moments of the analyzed system in both the gas phase and the solvent. According to our calculation results, the H-bond strength in solution is weaker than the gas phase and its energy decreases when the dipole moment of the solvent increases. It is well known that the higher the dipole moment, the higher the reactivity will be. In this complex, the largest and smallest dipole moments are observed in polar and non-polar solvents, respectively. The calculations suggest that the differences between the dipole moments in the FU-VB complex can be attributed to the nature of various solvents. In fact, the enhancement of dipole moment in pola solvents may be due to the charge value on the hydrogen atoms attached to the oxygen or nitrogen atoms with high electronegativity (see Figure1). Existence of the electronegative elements in FU and VB monomers facilitates thei interactions with together through $\mathrm{H}$-bonding formation with the hydrogen atoms. It can be mentioned that in the FU-VB complex, the hydrogen atoms in polar solvents carry the most positive charge, whereas the least positive charge on the hydrogen atoms exists in non-polar solvents. Therefore, the obtained results reveal a greater tendency of $\mathrm{VB}$ to form $\mathrm{H}$-bond as donor with respect to the FU.

\section{AIM analyses}

A topological analysis is carried out to calculate the electron density $(\rho)$ and its second derivative $\left(\nabla^{2} \rho\right)$ at the bond critical point (BCP) using the Bader theory of Atoms in Molecules (AIM) $[33,44]$. These parameters are often used as descriptors of $\mathrm{H}$-bond strength. Popelier [45] proposed that for the covalent bond (polar bond) interactions, the $\rho$ is large and value of the $\nabla^{2} \rho$ is negative. For closed shell interactions, such as ionic bonds, hydrogen bonds and van der Waals interactions, the $\rho$ is small and values of the $\nabla^{2} \rho$ are positive. Table 3 shows the calculated topological parameters of FU-VB complex in the gas phase and the various solvents. As shown in this Table, the increase of $\mathrm{O}_{\mathrm{VB}} \cdots \mathrm{H}_{\mathrm{FU}}$ bonc electron density $\left(\rho_{\mathrm{VB}} \cdots \mathrm{H}_{\mathrm{FU}}\right)$ in gas phase is accompanied with the decrease of electron density in solution phase. The relationships are reversed for the electron density of $\mathrm{O}_{\mathrm{FU}} \cdots \mathrm{H}_{\mathrm{VB}}$ bond $\left(\rho \mathrm{O}_{\mathrm{HU}} \cdots \mathrm{H}_{\mathrm{VB}}\right)$. In other words, the $\rho \mathrm{O}_{\mathrm{FU}} \cdots \mathrm{H}_{\mathrm{VB}}$ values show that the FU-VB complex has the least electron density in gas phase and the most electron density in solution phase. These results are in agreemen with the obtained geometrical parameters and the H-bond energies. However, it is worth mentioning that the shorter distance and greater electron density $\left(\rho_{\mathrm{O} \cdots \mathrm{H}}\right)$ at $\mathrm{O} \cdots \mathrm{H}$ contacts are attributed to greater strength of $\mathrm{H}$-bond.

In this complex, the established interactions also show the positive $\nabla^{2} \rho$ The positive values of $\nabla^{2} \rho$ at $\mathrm{BCPs}$ of $\mathrm{O}_{\mathrm{VB}} \cdots \mathrm{H}_{\mathrm{FU}}\left(\nabla^{2} \rho \mathrm{O}_{\mathrm{VB}} \cdots \mathrm{H}_{\mathrm{FU}}\right)$ and $\mathrm{O}_{\mathrm{FU}} \cdots \mathrm{H}_{\mathrm{VB}}$ $\left(\nabla^{2} \rho \mathrm{O}_{\mathrm{F}} \cdots \mathrm{H}_{\mathrm{VB}}\right)$ bonds indicate depletion of electronic charge along the bond paths (BPs), which is specification of the closed-shell interactions. The contour map and AIM molecular graph of FU-VB complex in water solution including bond paths and bond critical points are demonstrated in Figure 4. As it is obvious from this Figure, the position of the bond critical point strongly depends on electronegativity. In fact, the position of BCP is located closer to electropositive atoms, which leads to increasing of BCP electronegative atom distance and decreasing of $\mathrm{BCP}$ electropositive atom distance. Furthermore, the FU-VB complex is characterized by an eight-membered ring formed through a pair of two parallel intermolecular $\mathrm{H}$-bonds in $\mathrm{O}_{\mathrm{FU}} \cdots \mathrm{H}-\mathrm{O}_{\mathrm{VB}}$ and $\mathrm{O}_{\mathrm{VB}} \cdots \mathrm{H}-\mathrm{N}_{\mathrm{FU}}$ distances, where all of the eight atoms of the ring are coplanar. Therefore, interaction between $\mathrm{VB}$ and $\mathrm{FU}$ generates a cyclic system with a ring critical point (RCP) in intermolecular region (see Figure 4).
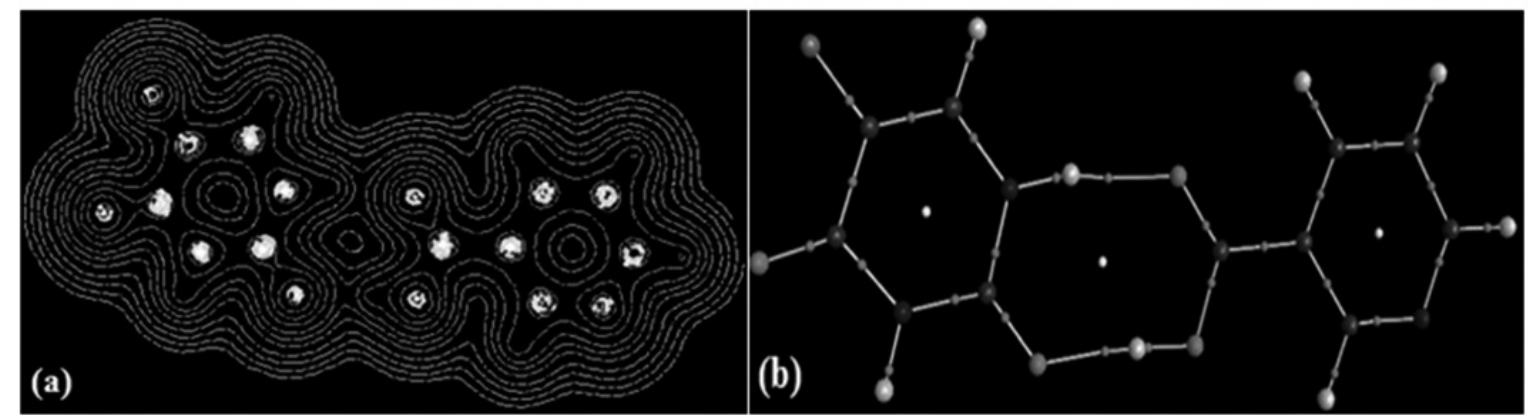
theory.

Figure 4. (a) The contour map and (b) the molecular graph of FU-VB complex obtained at the M05-2X/6-311++G(d,p) level of

Table 3. Topological parameters of FU-VB complex in different solvents at M05-2x/6-311++g(d,p) level of theory.

\begin{tabular}{|c|c|c|c|c|}
\hline Media & $\rho \mathrm{O}_{\mathrm{VB}} \cdots \mathrm{H}_{\mathrm{FU}}$ & $\nabla^{2} \rho \mathrm{O}_{\mathrm{VB}} \cdots \mathrm{H}_{\mathrm{FU}}$ & $\rho \mathrm{O}_{\mathrm{FU}} \cdots \mathrm{H}_{\mathrm{VB}}$ & $\nabla^{2} \rho \mathrm{O}_{\mathrm{FU}} \cdots \mathrm{H}_{\mathrm{VB}}$ \\
\hline Gas phase & 0.0337 & 0.1250 & 0.0439 & 0.1436 \\
\hline Water & 0.0301 & 0.1132 & 0.0462 & 0.1473 \\
\hline DMSO & 0.0301 & 0.1134 & 0.0461 & 0.1472 \\
\hline Methanol & 0.0302 & 0.1136 & 0.0461 & 0.1471 \\
\hline Ethanol & 0.0306 & 0.1149 & 0.0456 & 0.1463 \\
\hline Acetone & 0.0306 & 0.1151 & 0.0455 & 0.1462 \\
\hline Chloroform & 0.0317 & 0.1185 & 0.0448 & 0.1453 \\
\hline Ether & 0.0313 & 0.1174 & 0.0451 & 0.1456 \\
\hline & & & & \\
\hline
\end{tabular}


NBO analyses

A useful aspect of the NBO method is that it gives information about interactions in both filled and virtual spaces that could enhance the analysis of intermolecular interactions [46]. The $\mathrm{NBO}$ results show that the $\mathrm{LPO}_{\mathrm{VB}}$ $\rightarrow \sigma^{*} \mathrm{~N}-\mathrm{H}_{\mathrm{FU}}$ and $\mathrm{LPO}_{\mathrm{FU}} \rightarrow \sigma^{*} \mathrm{O}-\mathrm{H}_{\mathrm{VB}}$ donor-acceptor interactions are most important ones. The NBO method is used for quantitative analysis of the electron delocalization from the lone pair electrons of the oxygen atoms of $\mathrm{VB}$ (or FU) to the sigma antibonding orbitals of $\mathrm{N}(\mathrm{O})-\mathrm{H}$ bonds of FU (or VB) (see Table 4). In the studied complex, the lone pairs of oxygen atoms participate as donors and the $\sigma^{*}$-orbitals of $\mathrm{N}(\mathrm{O})-\mathrm{H}$ bonds act as acceptors.

Table 4. NBO analysis of FU-VB complex, occupation numbers of donor $\left(\mathrm{O} . \mathrm{N}_{\mathrm{C}_{\mathrm{D}}}\right)$ and acceptor $\left(\mathrm{O} . \mathrm{N}_{\mathrm{A}_{\mathrm{A}}}\right)$ orbitals and their energies (in kcal/mol) in some important orbitals.

\begin{tabular}{|c|c|c|c|c|c|c|}
\hline \multirow[t]{2}{*}{ Media } & \multicolumn{3}{|c|}{$\mathrm{LPO}_{\mathrm{VB}} \rightarrow \sigma^{*} \mathrm{~N}-\mathrm{H}_{\mathrm{FU}}$} & \multicolumn{3}{|c|}{$\mathrm{LPO}_{\mathrm{FU}} \rightarrow \sigma^{*} \mathrm{O}-\mathrm{H}_{\mathrm{VB}}$} \\
\hline & O.N..$_{D}$ & $\mathrm{O} \mathrm{N}_{\mathrm{A}}$ & $\mathrm{E}^{(2)}$ & O.N. ${ }_{D}$ & O.N..$_{A}$ & $\mathrm{E}^{(2)}$ \\
\hline Gas phase & 1.8722 & 0.0452 & 11.49 & 1.8548 & 0.0568 & 19.85 \\
\hline Water & 1.8723 & 0.0415 & 9.86 & 1.8545 & 0.0602 & 21.99 \\
\hline DMSO & 1.8723 & 0.0415 & 9.89 & 1.8545 & 0.0601 & 21.94 \\
\hline Methanol & 1.8723 & 0.0416 & 9.92 & 1.8545 & 0.0600 & 21.89 \\
\hline Ethanol & 1.8723 & 0.0419 & 10.06 & 1.8547 & 0.0594 & 21.52 \\
\hline Acetone & 1.8723 & 0.0420 & 10.09 & 1.8548 & 0.0593 & 21.47 \\
\hline Chloroform & 1.8723 & 0.0431 & 10.58 & 1.8550 & 0.0582 & 20.76 \\
\hline Ether & 1.8724 & 0.0427 & 10.42 & 1.8548 & 0.0587 & 21.03 \\
\hline
\end{tabular}

The NBOs occupation number and the calculated donor-acceptor interaction energies, $\mathrm{E}^{(2)}$, at $\mathrm{M} 05-2 \mathrm{X} / 6-311++\mathrm{G}(\mathrm{d}, \mathrm{p})$ level of theory are listed in Table 4. As shown in this Table, the stabilization energy of $\mathrm{LPO}_{\mathrm{vB}} \rightarrow \sigma^{*} \mathrm{~N}-$ $\mathrm{H}_{\mathrm{FU}}$ interaction decreases on passing from the gas phase to the solution phase. This trend is reversed for $\mathrm{LPO}_{\mathrm{FU}} \rightarrow \sigma^{*} \mathrm{O}-\mathrm{H}_{\mathrm{vB}}$ interaction. Furthermore, the results show that the occupation number changes of donor $\left(\mathrm{O} . \mathrm{N}_{\mathrm{D}}\right)$ orbitals for FU-VB complex in polar and non-polar solvents are approximately the same. On the other hand, the occupation number values of acceptor (O.N. ) orbitals in polar solvents are close to each other and do not change significantly (see Table 4). Therefore, it can be concluded that the polar solvents have a relatively low effect on the H-bond of FU-VB complex. It is interesting to note that the obtained results at the NBO basis are completely accordant with the found results in the AIM framework.

The charge transfers $\left(\mathrm{q}_{(\mathrm{CT})}\right)$ for the FU-VB complex in the different solvents are also studied. The NBO analysis can easily determine the transferred charge between the FU and VB monomers during complexation. In other words, the formation of a $\mathrm{H}$-bond leads to transfer of a certain amount of electronic charge from the proton-acceptor to the proton-donor molecule $[47,48]$. This reveals a rearrangement in electron density, which occurs within each monomer. In a NBO analysis, for each donor NBO (i) and acceptor NBO (j), the stabilization energy $E^{(2)}$ associated with $\mathrm{i} \rightarrow \mathrm{j}$ delocalization, is explicitly estimated by the following equation:

Table 5. The results of NBO analysis and the charge transfers $\left(\mathrm{q}_{\mathrm{CT}}\right.$ in e) at M05-2X/6- 311++G(d,p) level of theory.

\begin{tabular}{|c|c|c|c|c|c|c|}
\hline Media & $\begin{array}{c}\mathrm{Occ} \\
\mathrm{ValO}_{\mathrm{vB}}\end{array}$ & $\begin{array}{c}\mathrm{Occ} \\
\mathrm{ValO}_{\mathrm{FU}}\end{array}$ & $\begin{array}{c}\mathrm{S}(\%) \\
\mathrm{O}_{\mathrm{vB}}\end{array}$ & $\begin{array}{c}\mathrm{S}(\%) \\
\mathrm{O}_{\mathrm{FU}}\end{array}$ & LPO $\rightarrow \mathrm{q}_{(\mathrm{CT} 1)}$ N-H & LPO $\rightarrow \mathrm{\sigma}^{*} \mathrm{O}-\mathrm{H}$ \\
\hline Gas phase & 6.6837 & 6.6892 & 1.26 & 2.64 & -1.8998 & -1.9192 \\
\hline Water & 6.6830 & 6.6877 & 0.95 & 3.09 & -1.8910 & -1.9269 \\
\hline DMSO & 6.6831 & 6.6878 & 0.95 & 3.08 & -1.8968 & -1.9226 \\
\hline Methanol & 6.6831 & 6.6878 & 0.96 & 3.07 & -1.9026 & -1.9182 \\
\hline Ethanol & 6.6831 & 6.6881 & 0.98 & 2.99 & -1.9064 & -1.9163 \\
\hline Acetone & 6.6831 & 6.6881 & 0.99 & 2.99 & -1.9121 & -1.9118 \\
\hline Chloroform & 6.6832 & 6.6886 & 1.08 & 2.84 & -1.9290 & -1.9097 \\
\hline Ether & 6.6834 & 6.6884 & 1.06 & 2.90 & \\
\hline
\end{tabular}

The influence of various solvents on the occupation numbers of $\mathrm{Val}_{\mathrm{O}}$ is also analyzed. The results show that the $\mathrm{ValO}_{\mathrm{VB}}$ and $\mathrm{ValO}_{\mathrm{FU}}$ occupancies in the gas phase are equal to $6.6837 \mathrm{e}$ and $6.6892 \mathrm{e}$, respectively. As it can be seen in Table 5 , the occupation numbers are diminished in the presence of different solvents. The hybridization of $\mathrm{Lp}_{\mathrm{O}}$ corresponding to $\mathrm{sp}^{\mathrm{n}}$ is also studied by $\mathrm{NBO}$ method. Based on obtained results, the s character of this orbital is increased

$$
E^{(2)}=-q_{i} \frac{F_{i j}^{2}}{\varepsilon_{j}-\varepsilon_{i}}
$$

where $\mathrm{q}_{\mathrm{i}}$ is the donor orbital occupancy, $\varepsilon_{\mathrm{i}}$ and $\varepsilon_{\mathrm{j}}$ are diagonal elements (orbital energies) and $F(i, j)$ is the off-diagonal NBO Fock matrix element $[35,48]$. Table 5 shows the charge transfers $\left(\mathrm{q}_{\mathrm{CT}}\right)$ of the investigated complex in different solvents. Herein, the $\mathrm{q}_{(\mathrm{CT} 1)}$ and $\mathrm{q}_{\mathrm{C} \text { (T2) }}$ correspond to $\mathrm{LPO}_{\mathrm{VB}} \rightarrow \sigma^{*} \mathrm{~N}-\mathrm{H}_{\mathrm{FU}}$ and $\mathrm{LPO}_{\mathrm{FU}} \rightarrow \sigma^{*} \mathrm{O}-\mathrm{H}_{\mathrm{VB}}$ charge transfers, respectively. Our theoretical results demonstrate that the largest charge transfer $\mathrm{q}_{\mathrm{C} C \mathrm{C} 1)}$ is belonged to the complex in water and DMSO solvents. On the other hand, the obtained consequences reveal that the charge transfer $\mathrm{q}_{\text {(Cт2) }}$ in the ether and chloroform solvents is the greatest with respect to the other cases. As a result, the greater charge density on atoms of involved in H-bond leads to the more charge transfer of FU-VB complex in the different solvents. The obtained results also show that the values of charge transfer are not correlated with the H-bond energies in the related system. In fact, a reverse relationship exists between the H-bond energy values and their corresponding charge transfers. in the presence of different solvents by the FU monomer, but the reverse is true for the VB monomer. The increment of $\mathrm{s}$ character in the related solvents leads to withdrawing the electrons and a reduction in the Lewis base (O atom) properties of FU-VB complex (related to FU monomer). From the obtained results, it can be concluded that the trend of these changes is identical with the $\left|\mathrm{E}_{\mathrm{HB}}\right|, \rho_{\mathrm{BCP}}$ and $\mathrm{E}^{(2)}$ values. 
Frontier molecular orbital (FMO) analysis

The energy values of HOMO and LUMO and its energy gap reflect the chemical reactivity and the kinetic stability of molecules [49,50]. HOMO could act as electron donor, therefore, its energy is related to ionization potential. On the other hand, LUMO could act as electron acceptor, thus, the electron affinity of system depends on LUMO energy. In this study, the frontier orbitals are drawn to understand the bonding scheme of present complex. The positive phase is red and the negative one is green. Figure 5 reveals that in the titled complex, the HOMO is localized on 5FU fragment, while LUMO is confined by the VB3 fragment. Moreover, the HOMO of the FU-VB complex shows antibonding character at $\mathrm{N}-\mathrm{H}$ bond. In other words, there is no electronic projection over this bond.
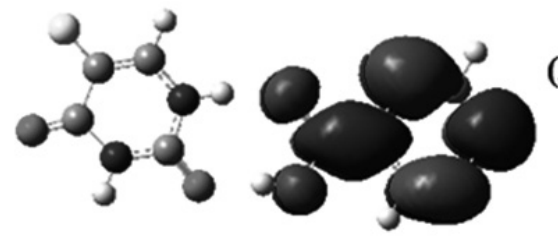

(First Excited State)

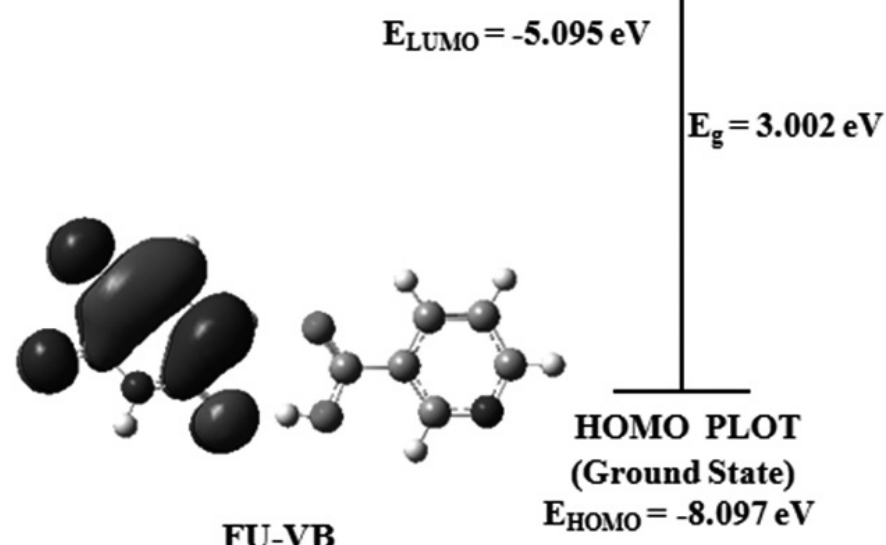

Figure 5. The HOMO and LUMO of FU-VB complex in water solvent obtained at the M05-2X/6-311++G(d,p) level of theory.

The calculated values of energy gap $\left(\mathrm{E}_{\mathrm{g}}\right)$, electronic chemical potential ( $\mu$ ) [51], chemical hardness $(\eta)$ [52], electrophilicity index $(\omega)$ [53] and electronegativity $(\chi)$ [54] ( $\chi$ is defined as the negative of $\mu$, as follows: $\chi=-\mu$ ) of FU-VB complex in the different solvents are presented in Table 6 . These parameters are important quantities, which have great use in characterizing the chemical systems and are calculated from HOMO and LUMO energies by using Koopman's theorem equations [55], as given below:

$$
\begin{aligned}
\eta & =\frac{\left(E_{\text {LUMO }}-E_{\text {HOMO }}\right)}{2} \\
\mu & =\frac{\left(E_{\text {LUMO }}+E_{\text {HOMO }}\right)}{2}
\end{aligned}
$$

where $\mathrm{E}_{\text {номо }}$ and $\mathrm{E}_{\text {Luмо }}$ are the highest occupied molecular orbital's energy and the lowest unoccupied molecular orbital's energy of the complex, respectively.

The energy gap in energy levels of a system is defined as $\mathrm{E}_{\mathrm{g}}=\mathrm{E}_{\mathrm{LUmo}}$ $\mathrm{E}_{\text {номо }}$. It is well known that energy gap between HOMO and LUMO can show whether the molecule is hard or soft. Hard molecules thus have a large HOMO-LUMO gap and soft molecules have a small one. As shown in Table 6 , the $\mathrm{E}_{\text {o }}$ in polar solvents is higher than non-polar solvents, while it is lower than solution in gas phase. In fact, the increment of energy gap in polar solvents is due to the high chemical stability and low chemical reactivity of the related complex in these solvents. Our theoretical results also reveal that the gap energy of the studied system in water and the other polar solvents does not change appreciably. Therefore, the stability of FU-VB complex in these solvents is negligible (see Table 6). It is also worth mentioning that the most stable systems have the highest chemical hardness. The obtained data from Table 6 show that the value of hardness in polar solvents is more than other cases. As a result of our calculations, the FU-VB complex in the gas phase is the more reactive and softer than the others.

The results collected in Tables 2 and 6 confirm dependencies known for the energetic parameters and hardness values. For instance, the linear correlation coefficients for the dependence between hardness value versus stability order and binding energy are equal to 0.945 and 0.948 , respectively. The following equations illustrate these relationships:

$$
\begin{aligned}
& \eta=(-0.0003) \text { S.O. }+1.5004 \\
& \eta=(0.0003) \text { B.E. }+1.5124
\end{aligned}
$$

These correlations reveal that the increment of hardness is accompanied with the reduction in the values of binding energy, and also the increase in the stability.

Table 6. Orbital energies (HOMO and LUMO), energy gap $\left(\mathrm{E}_{\mathrm{g}}\right)$, hardness $(\eta)$, chemical potential $(\mu)$, electronegativity $(\chi)$ and electrophilicity index $(\omega)$ of FU-VB complex (in eV) in the selected solvents.

\begin{tabular}{|c|c|c|c|c|c|c|c|}
\hline Media & $\mathrm{E}_{\text {номо }}$ & $\mathrm{E}_{\text {LUмо }}$ & $\mathrm{E}_{\mathrm{g}}$ & $\eta$ & $\mu$ & $\chi$ & $\omega$ \\
\hline Gas phase & -8.080 & -5.093 & 2.987 & 1.494 & -6.586 & 6.586 & 14.521 \\
\hline Water & -8.097 & -5.095 & 3.002 & 1.501 & -6.596 & 6.596 & 14.490 \\
\hline DMSO & -8.097 & -5.095 & 3.002 & 1.501 & -6.596 & 6.596 & 14.491 \\
\hline Methanol & -8.096 & -5.095 & 3.002 & 1.501 & -6.595 & 6.595 & 14.491 \\
\hline Ethanol & -8.095 & -5.095 & 3.000 & 1.500 & -6.595 & 6.595 & 14.501 \\
\hline Acetone & -8.095 & -5.095 & 2.999 & 1.500 & -6.595 & 6.595 & 14.501 \\
\hline Chloroform & -8.090 & -5.095 & 2.995 & 1.497 & -6.593 & 6.593 & 14.512 \\
\hline Ether & -8.091 & -5.095 & 2.996 & 1.498 & -6.593 & 6.593 & 14.506 \\
\hline
\end{tabular}

The chemical potential is also known by the opposite behavior to that of hardness. As shown in Table 6, the chemical potential values of the FU-VB complex are negative; hence, the considered complex in all of the phases is stable. In addition, the FU-VB complex shows the most electronegativity value in polar solvents with respect to the other cases. Thus, this complex is the best electron acceptor in these solvents (see Table 6). In 1999, Parr defined the electrophilicity index $(\omega)[53,56]$, which gives a measure of the energy stabilization of a molecule when it acquires an additional amount of electron density from the environment. The equation of electrophilicity index is given as follows:

$$
\omega=\frac{\mu^{2}}{2 \eta}
$$

The electrophilicity index classifies molecules as the weak electrophiles with $\omega<0.8 \mathrm{eV}$, the medium electrophiles with $0.8<\omega<1.5 \mathrm{eV}$ and also the strong electrophiles with $\omega>1.5 \mathrm{eV}$ [57]. As a result of our calculations, the maximum and minimum values of the electrophilicity index for the FU-VB complex are observed in the gas phase and the polar solvents, respectively. The results are collected in Table 6. 
Molecular electrostatic potential (MEP)

The MEP is very useful in research of molecular structure with its physiochemical property relationship [58]. It can simultaneously display useful information about the size and shape of complexes and electrophilic and nucleophilic regions. Gauss View 5.0 is employed to constrict molecular electrostatic potential map and total electron density by the M05-2x/6$311++\mathrm{g}(\mathrm{d}, \mathrm{p})$ method. In drug receptors, it is a very useful descriptor in understanding sites for H-bonding interactions. The different values of the electrostatic potential at the surface are represented by different colors; red represents regions of most negative electrostatic potential, blue represents regions of most positive electrostatic potential and green represents regions of zero potential. Potential increases in the order red $<$ orange $<$ yellow $<$ green $<$ blue. In this study, the molecular electrostatic potential 3D plot of the FUVB complex in water solvent is drawn in Figure 6. The results show that the regions of negative electrostatic potential (indicated by red) are usually used to recognize hydrogen-bond-acceptor sites and for evaluation of the hydrogenbond-donating sites the regions of positive (indicated by blue) are considered. As shown in Figure 6, the negative potential site is on electronegative oxygen atoms and the positive potential site is around the hydrogen atoms. Thus, it can be stated that the hydrogen atoms indicate the strongest attraction and oxygen atoms show the strongest repulsion. These sites give information about regions that the complex can encompass intermolecular interactions.

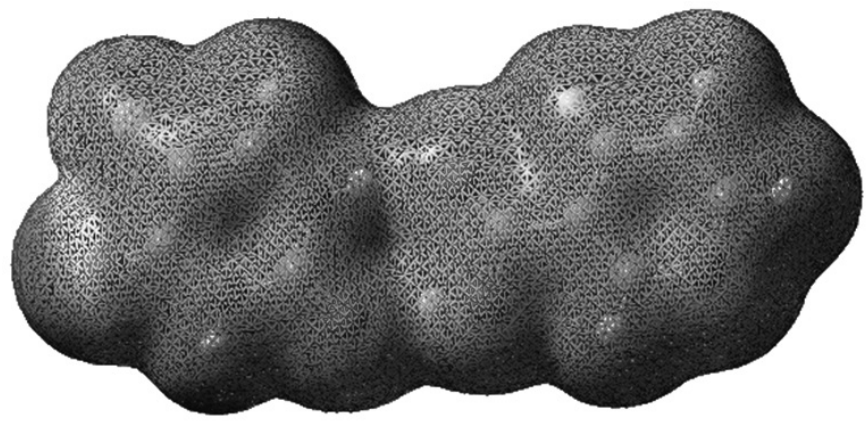

Figure 6. Electrostatic potential of the FU-VB complex in water solvent; color coding: red (very negative), yellow (slightly negative), light blue (positive) and dark blue (very positive)

\section{CONCLUSION}

In this study, the quantum chemistry calculations at the M05-2X/6$311++\mathrm{G}(\mathrm{d}, \mathrm{p})$ level of theory are performed to investigate the effect of different solvents on the stability order, binding energy and H-bond strength of FU-VB complex. The theoretical results based on the average of the calculated H-bond energies, predict the H-bond strength of FU-VB complex in gas phase is more than solution phase and in the polar solvents is approximately the same and lower than non-polar solvents. Our findings also confirm that when the solvent effect is applied the binding energies of complex are significantly changed. The results show that the binding energy in solution phase is lower than the gas phase. Therefore, the stability of the studied complex increases in solution phase with respect to the gas phase. Comparing trend of the binding energies with the H-bond energies of FU-VB complex shows a direct relationship between them. The obtained results also show that by increasing of the solvents polarity, the binding energy of the considered complex decreases. Therefore, formation of FU-VB complex in ether, as non-polar solvent, is more favorable with respect to other polar solvents, energetically. In addition, the AIM and $\mathrm{NBO}$ analyses are employed to elucidate the nature of intermolecular $\mathrm{H}$-bond interactions in FU-VB complex. In this complex, the established interactions show the positive $\nabla^{2} \rho$. The positive values of $\nabla^{2} \rho$ at BCPs of $\mathrm{O}_{\mathrm{VB}} \cdots \mathrm{H}_{\mathrm{FU}}$ and $\mathrm{O}_{\mathrm{FU}} \cdots \mathrm{H}_{\mathrm{YB}}$ bonds indicate depletion of electronic charge along the bond paths, which is specification of closed-shell interactions. It is interesting to note that the obtained results at the NBO basis are completely accordant with the found results in the AIM framework. The analysis of HOMO and LUMO is also performed to evaluate the electronic properties, stability and reactivity of the FU-VB complex. Our theoretical results reveal that the energy gap and hardness of the studied complex increase in the presence of polar solvents. As a result of our calculations, the FU-VB complex has the high chemical stability and low chemical reactivity in the polar solvents with respect to the other cases. Therefore, the polar solvents are safe and can be used in biological research.

\section{REFERENCES}

1.- (a) G. A. Jeffrey, D. G. Truhlar (Ed), An Introduction to Hydrogen Bonding. Oxford University Press, New York, 1997. (b) E. C. Hulme (Ed), Receptor-Ligand Interactions: A Practical Approach. Oxford University Press, Oxford, 1992.

2.- H. R. Masoodi, A. Ebrahimi, M. Habibi, Chem. Phys. Lett. 483, 43, (2009)

3.- G. R. Desiraju, T. Steiner, The Weak Hydrogen Bond: In Structural Chemistry and Biology. Oxford University Press, USA, 2001.

4.- D. Hadz i, Theoretical Treatments of Hydrogen Bonding. John Wiley \& Sons, Chichester, 1997.

5.- P. Hobza, Z. Havlas, Chem. Rev. 100, 4253, (2000)

6.- W. Wang, Y. Zhang, K. Huang, Chem. Phys. Lett. 411, 439, (2005)

7.- A. K. Roy, A. J. Thakkar, Chem. Phys. 312, 119, (2005)

8.- R. Wysokinski, D. C. Biennko, D. Michalska, Th. Zeegers-Huyskens, Chem. Phys. 315, 17, (2005)

9.- A. Ebrahimi, H. Roohi, M. Habibi, M. Mohammadi, R. Vaziri, Chem. Phys. 322, 289, (2006)

10.- A. Ebrahimi, H. Roohi, M. Habibi, M. Hasannejad, Chem. Phys. 327, 368, (2006)

11.- A. Ebrahimi, M. Habibi, H. R. Masoodi, A. R. Gholipour, Chem. Phys. $355,67,(2009)$

12.- G. A. Jeffrey, W. Saenger, Hydrogen Bonding in Biology and Chemistry. Springer-Verlag, Berlin, 1991.

13.- C. Estarellas, A. Frontera, D. Quiñonero, P. M. Deyà, Chem. Phys. Lett. 479, 316, (2009)

14.- C. H. Wu, C. Chen Wu, Y. S. Ho, J. Cancer Mol. 3, 15, (2007)

15.- D. J. Brown, Heterocyclic Compounds: Thy Pyrimidines. Interscience, New York, 1994.

16.- A. F. Pozharskii, A. T. Soldatenkov, A. R. Katrizky, Heterocycles in Life and Society. John Wiley and Sons, New York, 1997.

17.- A. Shah, E. Nosheen, F. Zafar, S. Noman uddin, D. D. Dionysiou, A Badshah, Z. Rehman, G. Shahzada Khan, Journal of Photochemistry and Photobiology B: Biology. 117, 269, (2012)

18.- J. L. Arias, Molecules. 13, 2340, (2008)

19.- K. Zare, F. Najafi, H. Sadegh, R. Shahryari ghoshekandi, Journal Of Nanostructure in Chemistry. 3, 71, (2013)

20.- M. P. Findlay, M. O. Leach, Anticancer Drugs. 5, 260, (1994)

21.- Institute of Medicine "Niacin", Dietary Reference Intakes for Thiamin, Riboflavin, Niacin, Vitamin B6, Folate, Vitamin B12, Pantothenic Acid, Biotin, and Choline. Washington DC, The National Academies Press, 123, 1998.

22.- "Niacin and niacinamide (Vitamin B3)". MedlinePlus, US National Library of Medicine, National Institutes of Health, 2016.

23.- S. M. Bhairi, C. Mohan, Calbiochem. 1, (2001)

24.- L. C. Javois, Methods in Molecular Biology. 115, 46, (1999)

25.- M. M. Al-Oqail, E. S. Al-Sheddi, M. A. Siddiqui, J. Musarrat, A. A. AlKhedhairy, N. N. Farshori, Pharmacogn. Mag. 11, 598, (2015)

26.- S. Gayatri, C. Uma Maheswara Reddy, K. Chitra, V. Parthasarathy, Pharmacognosy Research. 7, 198, (2015)

27.- I. Trawczyńska, M. Wójcik, Biotechnology \& Biotechnological Equipment. 29, 72, (2015)

28.- J. M. Baust, R. Van Buskirk, J. G. Baust, In Vitro Cell. Dev. Biol. Anim. $36,262,(2000)$

29.- S. Y. Lee, H. J. Park, C. Best-Popescu, S. Jang, Y. K. Park, PLoS. One. 10(12), e0145327, (2015)

30.- M. Frisch, G. Trucks, H. Schlegel, et al., Gaussian 03, revision D.01, Gaussian Inc., Wallingford, CT, 2004.

31.- S. Miertus, E. Scrocco, J. Tomasi, J. Chem. Phys. 55, 117, (1981)

32.- E. Espinosa, E. Molins, C. Lecomte, Chem. Phys. Lett. 285, 170, (1998)

33.- R. F. W. Bader, Atoms in molecules: a quantum theory. Oxford University, New York, 1990

34.- F. Biegler Ko"nig, J. Scho"nbohm, J. Comput. Chem. 23, 1489, (2002)

35.- A. E. Reed, L. A. Curtiss, F. Weinhold, Chem. Rev. 88, 899, (1988)

36.- E. D. Glendening, A. E. Reed, J. E. Carpenter, F. Weinhold, NBO, version 3.1 (in), Gaussian, Inc., Pittsburg, CT, 2003.

37.- S. J. Grabowski, W. A. Sokalski, E. Dyguda, J. Leszczyn'ski, J. Phys. Chem. B. 110, 6444, (2006)

38.- Z. Desta, B. A. Ward, N. V. Soukhova, D. A. Flockhart, J. Pharmacol. Exp. Ther. 310, 1062, (2004)

39.- H. Raissi, M. Yoosefian, S. Khoshkhou, Comput. Theor. Chem. 983, 1, (2012) 
40.- H. Raissi, F. Farzad, E. S. Nadim, M. Yoosefian, H. Farsi, A. Nowroozi, D. loghmaninejad, Int. J. Quantum Chem. 112, 1273, (2012)

41.- H. Raissi, M. Yoosefian, F. Mollania, F. Farzad, A. Nowroozi, D. loghmaninejad, J. Comput. Theor. Chem. 966, 299, (2011)

42.- M. Yoosefian, Z. Jafari Chermahini, H. Raissi, A. Mola, M. Sadeghi, J. Mol. Liq. 203, 137, (2015)

43.- M. Yoosefian, A. Mola, J. Mol. Liq. 209, 526, (2015)

44.- J. Liu, X. Xia, Y. Li, H. Wang, Z. Li, Struct. Chem. 24, 251, (2013)

45.- P. L. A. Popelier, J. Phys. Chem. A. 102, 1873, (1998)

46.- M. Noei, S. Suzangarzadeh, S. Golshani, A. Tahan, Russian J. Phys. Chem. A. $85,993,(2011)$

47.- P. Hobza, V. Spirko, H. L. Selzle, E. W. Schlag, J. Phys. Chem. A. 102 , 2501, (1998)

48.- L. Hokmabady, H. Raissi, A. Khanmohammadi, Struct. Chem. 27, 487, (2016)
49.- I. Fleming, Frontier Orbitals: Organic Chemical Reactions. John Wiley and Sons, New York, 1976.

50.- J. C. Jesintha, T. S. Xavier, G. Lukose, J. I. Hubert, Spectrochimica. Acta. Part A. 85, 66, (2012)

51.- P. K. Chattaraj, A. Poddar, J. Phys. Chem. A. 103, 8691, (1999)

52.- R. G. Pearson, Chemical Hardness - Applications from Molecules to Solids. Weinheim: VCH-Wiley, 1997.

53.- R. G. Parr, L. von Szentpaly, S. Liu, J. Am. Chem. Soc. 121, 1922, (1999)

54.- K. D. Sen, C. K. Jorgensen, Electronegativity, Structure and Bonding. Springer Verlag, New York, 1987.

55.- T. Koopmans, Phys. 1, 104, (1933)

56.- L. R. Domingo, M. Ríos-Gutiérrez, P. Pérez, Molecules. 21, 748, (2016)

57.- L. R. Domingo, M. J. Aurell, P. Pérez, R. Contreras, Tetrahedron. 58, 4417, (2002)

58.- J. S. Murray, K. Sen, Molecular Electrostatic Potentials, Concepts and Applications. Elsevier, Amsterdam, 1996. 